\title{
Um marxismo transviado ${ }^{1}$
}

\section{Rafael Dias Toitio ${ }^{2}$}

Resumo: A proposta do texto é contribuir para a reflexão de como o marxismo pode subsidiar a análise das relações de gênero e sexualidade, em diálogo com algumas categorias e perspectivas desenvolvidas pelo pós-estruturalismo. Para tanto, parto do questionamento da ideia, vastamente presente na esquerda marxista, de que a luta pela diversidade sexual e de gênero é uma luta simplesmente particular e identitária. Depois, elaboro alguns apontamentos sobre como o marxismo pode colaborar para o desenvolvimento de uma análise da articulação das relações de poder e de estratégias políticas que contribuam para o avanço das lutas de sexualidade e gênero.

Palavras-chave: Diversidade sexual e de gênero; Marxismo; Pósestruturalismo.

Abstract: The purpose of the text is to contribute to the reflection on how Marxism can subsidize the analysis of gender and sexuality relations, in dialogue with some categories and perspectives developed by poststructuralism. To that end, I begin by questioning the idea, widely present in the Marxist left, that struggle for sexual and gender diversity is simply a particular and identitarian struggle. Then, I elaborate some notes on how Marxism can contribute to develop an analysis of the

\footnotetext{
${ }^{1}$ A utilização do termo transviado foi inspirada em Bento (2014) como uma tradução do termo queer. Mesmo que este tenha ganhado maior visibilidade nos últimos anos, acredito que no Brasil ele esteja muito ligado à academia e a alguns setores da arte, fazendo pouco sentido ao conjunto da população e dos movimentos sociais e partidos políticos. Aproveito para agradecer a Hélio Ázara de Oliveira pela leitura crítica do artigo e pelas preciosas considerações.

${ }^{2}$ Doutor em Ciências Sociais pela Unicamp. E-mail: rtoitio@yahoo.com.br.
} 
articulation of power relations and political strategies that contribute to advance the struggles of sexuality and gender.

Keywords: Sexual and gender diversity; Marxism; Poststructuralism.

Uma vantagem de vivermos em um período de intensas transformações sociais é o fato de podermos testemunhar a história e suas nuances de maneira tão íntima. Desde o final dos anos 1960, houve mudanças significativas na forma das sociedades ocidentais compreenderem o gênero e a sexualidade. No Brasil, esse processo se tornou mais visível em fins dos 1970, com a emergência de mobilizações e movimentos sociais que fariam romper a ditatura militar, o que incluiu o surgimento de organizações feministas e de gays e lésbicas. As décadas posteriores, para quem a vivenciou, foram de um lento processo de transformações nas visões, atitudes e práticas surgidas nas relações de gênero e sexualidade - ainda que isso tenha vindo acompanhado contraditoriamente de momentos de recrudescimento conservador, que têm se expressado de várias maneiras, incluindo as formas de violência machista e LGBTfóbica.

Esse processo gerou a necessidade das teorias sociais e políticas repensarem suas perspectivas e reflexões sobre o tema, formando novas correntes e metodologias e gerando novas divisões teóricas. Com o marxismo não foi diferente. Pelo menos desde os 1970, um rico debate se desenvolveu com o feminismo, ainda que muitas vezes isso fosse tratado como uma subárea, um subtema da teoria. Além disso, essa discussão se concentrou na questão (não menos importante) da mulher heterossexual e apenas nos últimos anos têm surgido no Brasil estudos marxistas preocupados com a diversidade sexual e de gênero, o que tem gerado novos questionamentos, tensões e reflexões sobre um tema cada vez mais visível e presente nos espaços públicos. Assim a articulação do marxismo com outras teorias feministas (pósestruturalista e materialista francesa) para explicar os processos relacionados às relações de sexualidade e gênero é uma operação em

\begin{tabular}{l|l}
\hline 62 & Um marxismo transviado
\end{tabular} 
construção no Brasil, que tem crescido nos estudos acadêmicos e nas elaborações dos movimentos sociais e partidos de esquerda.

O presente artigo tem o objetivo de contribuir para essa discussão, ao se propor uma reflexão de como o marxismo pode subsidiar a análise das relações de gênero e sexualidade, em diálogo com algumas categorias e perspectivas desenvolvidas pelo pós-estruturalismo. Apesar das diferenças e "rupturas" traçadas entre ambas as teorias, penso que não são teorias antagônicas, sendo possível estabelecer uma articulação entre essas duas formas de investigação, evidenciando os pontos em comum e os divergentes, e os analisando à luz dos acontecimentos históricos concretos e debatendo com o desenvolvimento teórico atual. Aqui, cabe indicar que tanto o marxismo quanto o pós-estruturalismo não são abordagens teóricas monolíticas ou facilmente redutíveis a estereótipos e a classificações rasteiras. Ambas são teorias complexas, com várias correntes muito diferentes entre si e, por isso, devem ser entendidas em sua pluralidade: como não existe marxismo no singular, também não existe pós-estruturalismo no singular. Por isso, o diálogo proposto será, mais especificamente, com as contribuições de Michel Foucault e de Judith Butler.

No intuito de desenvolver a referida discussão, na primeira seção, parto do questionamento de duas ideias largamente presentes na esquerda marxista sobre o tema: (a) a luta pela diversidade sexual e de gênero é uma luta simplesmente identitária e particular de um grupo social? (b) A bandeira "o corpo é meu" é uma reivindicação individualista e por isso (neo)liberal? ${ }^{3}$ Evidentemente, esses dois questionamentos estão ligados a uma pré-noção muito arraigada de que as lutas e bandeiras dos movimentos LGBT e feminista têm dividido os esforços da esquerda no processo de transformação social ao focarem em reivindicações (supostamente) individualistas e específicas,

\footnotetext{
${ }^{3}$ Essa é uma visão largamente presente nos discursos e teorizações da esquerda marxista, não sendo, portanto, o caso de individualizar a presente crítica apontando autores e autoras que subscrevem tal visão.
} 
e bloqueando os impulsos revolucionários. Na segunda seção, elaboro alguns apontamentos sobre como o marxismo pode ajudar o desenvolvimento de uma análise da articulação das relações de poder e para a construção de estratégias e ação políticas que contribuam para o avanço das lutas de sexualidade e gênero.

\section{Lutas particulares?}

A emergência dos assim denominados "novos movimentos sociais", a partir dos anos 1960, trouxe novos desafios de teorização ao pensamento marxista principalmente porque tais movimentos se diferenciavam do movimento operário em termos de reivindicação, organização, identidade coletiva e estratégias. As primeiras respostas marxistas, longe de procurarem compreender os movimentos emergentes a partir de seus próprios termos, foram hábeis em oferecer explicações que se ajustavam às principais teses e perspectivas em voga (no marxismo) naquele momento. Assim, ganharam força desde visões de inspiração stalinista, de que esses movimentos não passariam de manifestações liberais e pequeno-burguesas, que se centravam em questões individuais e que fariam romper com o esforço coletivo revolucionário; até outras explicações fundamentadas no marxismo humanista, que ao pressupor uma essência humana que se realizaria apenas com o trabalho livre, criativo e "emancipador", afirmava a luta de classes como universal e as demais como particulares e, logo, a luta de classes como a principal e as demais como secundárias.

É necessário interrogar se essas visões hoje são politicamente produtivas e problematizar as implicações de cultivarmos uma análise teórica que hierarquiza as relações sociais desiguais. Para iniciar o debate, recorro ao instigante artigo El marxismo e lo meramente cultural, elaborado por Butler em meados dos 1990 e que já colocava uma questão muito semelhante da que foi aqui anunciada. $\mathrm{O}$ artigo, que tem o mérito de tratar de modo resumido alguns pontos cruciais para a

\begin{tabular}{l|l}
\hline 64 & Um marxismo transviado
\end{tabular} 
presente discussão, era uma crítica dirigida àquela parte dos marxistas que insistia em classificar a política construída em torno da sexualidade e do gênero como "fragmentadora, identitária e particularista" e que estaria localizada na "esfera" cultural. Sobretudo, a sexualidade estaria fora da "esfera" econômica sendo que a política queer representaria o extremo cultural da politização (BUTLER, 2000, p. 109, 114).

Para responder a essa ideia, a autora recorreu ao próprio debate marxiano, presente $n^{\prime} A$ ideologia alemã, sobre o papel da família e da relação entre homem e mulher na reprodução social e, de forma mais contundente, lembrou a importância desse debate para o desenvolvimento do pensamento das feministas socialistas, nos anos 1970 e 1980. Estas enfatizaram um trecho de A origem da família, da propriedade privada e do Estado, de Engels, que afirmava que para a concepção materialista, o fator determinante da história é, em última instância, a produção e reprodução imediata da vida. Essa reprodução envolveria, por um lado, a produção dos meios de subsistência e, por outro, a produção dos próprios seres humanos, sendo a reprodução sexual um elemento que deveria ser incorporado às condições materiais de existência e, por isso, constitutivo da economia política. Assim, esses debates feministas analisavam, como parte integrante da "produção dos seres humanos", a produção social do gênero, a regulação social da família e, mais exatamente, da reprodução da família heterossexual como lugar de reprodução de pessoas heterossexuais aptas a se incorporarem à família. Tal processo atuaria na produção de pessoas de acordo com modelos sociais que foram úteis para o desenvolvimento do capitalismo (BUTLER, 2000, p. 115-116).

Nesse sentido, a autora afirmou que o "âmbito" da reprodução está circunscrito pela regulação sexual, sendo por meio das formas obrigatórias de exclusão que se define e naturaliza a esfera da reprodução. Tais formas obrigatórias são resultado do mesmo processo de construção da hegemonia heterossexista e de seus "gêneros", de modo que as formas de sexualidade excluídas e produzidas como 
aberrantes são uma ameaça fundamental para o funcionamento adequado da economia politica capitalista. Assim, para ela, não faz sentido entender esse processo como meramente cultural, uma vez que ele tem um caráter "econômico, ligado ao reprodutivo, [que] está necessariamente vinculado com a reprodução da heterossexualidade" (BUTLER, 2000, p. 118; tradução livre).

Vale mencionar que a proposta teórica de Butler era fazer uma espécie de "paródia" do marxismo, isto é, elaborar um debate a partir dos termos e dos elementos teóricos deste. O seu intuito com isso era estabelecer uma "identificação temporal" com o marxismo, procurando responder a questionamentos que geram divisões "desnecessárias" na esquerda (BUTLER, 2000, p. 110). Por mais que para a autora a identificação de sua teoria com o marxismo fosse transitória, cabe indagar o motivo que a levou a enfocar justamente esses argumentos e não outros, dentro de uma teoria que abriga uma grande variedade de autores/as e perspectivas. Não seria essa a leitura do marxismo que permitiria um diálogo com as contribuições de Butler (e de Foucault)? Interessante que a filósofa pós-estruturalista, no debate com o que ela denominou de marxistas neoconservadores, recorreu justamente ao elemento fundante do pensamento marxista, que o fazia romper com o idealismo hegeliano, ao defender a centralidade da economia, a partir de uma noção ampla do "econômico". Como lembra György Lukács, a originalidade inovadora de Marx, já nos Manuscritos econômicofilosóficos, foi tratar as categorias econômicas "como as categorias da produção e reprodução da vida humana, tornando possível uma exposição ontológica do ser social sobre bases materialistas" (LUKÁCS, 2012, p. 285).

Insistir na perspectiva marxista para pensar as relações de gênero e de sexualidade apenas tem sentido se nos preocuparmos em focar na dialética que existe entre produção e reprodução social. Por um lado, isso permite evidenciar como essas relações são também "estruturantes", no sentido de permanecerem ao longo do tempo

\begin{tabular}{l|l}
\hline 66 & Um marxismo transviado
\end{tabular} 
e determinarem ${ }^{4}$ a "organização" da nossa sociedade e de suas práticas. Afinal, pelo menos nos países capitalistas ocidentais, já não nascemos pertencentes a uma posição de classe e, também, como corpos generificados e compulsoriamente heterossexuais? E as necessidades surgidas da produção material de corpos (por meio do trabalho reprodutivo e da construção de desejos, afetos, "performances", práticas-de-cuidado-de-si etc.) não condicionaram a produção das formas jurídicas, políticas e ideológicas hegemônicas relacionadas à sexualidade e ao gênero? Vale lembrar que a formação dos grandes Estados imperialistas, no século XIX, dependeu em grande medida do aumento inédito de suas populações, não faltando a proliferação de leis nacionais que oficializavam o heterossexismo como prática obrigatória, além da difusão do discurso científico que oferecia uma explicação "racional" da diversidade sexual e de gênero como patologia e aberração.

Apesar das diferenças com o marxismo, Foucault em sua História da sexualidade desenvolveu importantes análises para refletirmos sobre a formação do capitalismo, mas por um caminho que procurava evidenciar "a importância assumida pelo sexo como foco de disputa política" (FOUCAULT, 1988, p. 158). Para ele, o sexo "se encontra na articulação entre dois eixos ao longo dos quais se desenvolveu toda a tecnologia política da vida". Por um lado, a disciplinalização do corpo: "o adestramento, intensificação e distribuição de forças, ajustamento e economia das energias". Do outro, a regulação sexual como forma de regular as populações por meio de um conjunto de técnicas que agem no controle populacional, "intervenções que visam todo o corpo social ou grupos tomados globalmente. O sexo é acesso, ao mesmo tempo, à vida do corpo e à vida da espécie. Servimo-nos dele como

\footnotetext{
${ }^{4}$ Determinação deve ser entendida sempre no sentido apontado por Raymond Williams: não como a ação de uma causa externa que prefigura por completo, que controla totalmente uma atividade ulterior, e sim pensada a partir da experiência e da prática social, "de fixar limites e de exercer pressões (por força externa ou por leis internas de um desenvolvimento particular)" (WILLIAMS, 2011, p. 44).
} 
matriz das disciplinas e como princípio das regulações" (FOUCAULT, 1988, p. 159). Uma das conclusões de Foucault é que esse biopoder foi indispensável para o "desenvolvimento do capitalismo, que só pôde ser garantido à custa da inserção controlada dos corpos no aparelho de produção e por meio de um ajustamento dos fenômenos de população aos processos econômicos" (FOUCAULT, 1988, p. 153).

Nota-se que essa interpretação longe de ser antagônica ao marxismo, procura complementá-lo ${ }^{5}$. Uma das questões centrais da proposta analítica de Foucault e Butler é conceber a sexualidade e o gênero a partir de uma perspectiva historicista radical. Tal perspectiva se alinha com a indicação de Antonio Gramsci que chamava atenção para sublinharmos, na expressão materialismo histórico, o segundo e não o primeiro termo, uma vez que a contribuição maior do marxismo era sua capacidade de se constituir como "historicismo absoluto, a mundanização e terrenalidade absoluta do pensamento", viés pelo qual deveria ser "buscado o filão da nova concepção de mundo" (GRAMSCI, 2006, p. 155). Gramsci estava se referindo sobre uma nova sociedade e uma nova forma de sentir e conceber a vida, alimentadas pela perspectiva da historicidade das relações sociais.

Marx foi pioneiro na denúncia contra as visões essencialistas e naturalizantes de práticas sociais, sobretudo aquelas ligadas às desigualdades de classes, acentuando como a atribuição do caráter de "natural" a questões históricas e sociais, tornam-nas "imunes" à mudança. Nas Teses sobre Feuerbach, ele afirmou que "a essência humana não é uma abstração intrínseca ao indivíduo isolado. Em sua realidade, ela é o conjunto das relações sociais" (MARX, 2007, p. 534). Marx ironizou ao utilizar o termo essência para mostrar que

\footnotetext{
5 Penso que é possível estabelecer um diálogo de Foucault e o pós-estruturalismo com o marxismo assim como fez Nicos Poulantzas, em O Estado, o poder e o socialismo. De acordo com Bob Jessop (2007, p. 142), Poulantzas rejeitava o projeto teórico e epistemológico mais geral de Foucault, mas valorizava a sua análise de técnicas específicas de poder e de certos aspectos da forma Estado.
}

\begin{tabular}{l|l}
\hline 68 & Um marxismo transviado
\end{tabular} 
não existe uma "essência humana", pelo menos não de forma imutável e universal. Nota-se que ele não reduziu sua resposta às relações sociais de produção, e sim ao conjunto das relações sociais que não pode ser compreendido se abstraído do "curso da história".

No entanto, considerar a historicidade dos processos implica em considerar a historicidade da própria teoria. Afinal, o marxismo não permanece vivo e atual devido ao devaneio de professores/as e militantes de esquerda, mas sim porque as próprias relações capitalistas continuaram se expandindo. Por outro lado, historicizar a teoria garante uma leitura dialética dos clássicos: reconhecendo os traços de evolucionismo que permeiam suas obras; mas, também, evitando críticas infundadas que rejeitam o marxismo devido à ambiguidade em naturalizar as relações de gênero e de sexualidade. Por mais que as teorizações clássicas possam apresentar concepções heterossexistas e machistas, não é caso de acusá-las de negligenciar essas questões. Se debates e movimentos (mesmo que incipientes) que reivindicavam o direito civil e político de mulheres e homossexuais já existiam nas últimas décadas do século XIX e vão se desenvolvendo no decorrer do século XX, foi somente a partir do final dos anos 1960 e 1970 que esses movimentos se fortaleceram e se espraiaram reivindicando uma mudança mais global nas práticas e relações sociais a partir de uma concepção radical da historicidade destas.

A abordagem histórica da sexualidade, do gênero e do sexo, que já vinha se constituindo - sendo O segundo sexo (1949), de Simone de Beauvoir, uma referência fundamental - ganhou consistência como expressão teórica com a emergência do movimento político mais amplo que surgiu no final dos anos 1960, com o movimento pelos direitos civis de negros/as, a "segunda onda" do movimento feminista, a eclosão do movimento de "liberação gay", e outros. Os ideais de emancipação e a contracultura alimentavam a construção de movimentos, teorias, concepções e práticas políticas que, entre outros elementos, evocavam questões como autonomia, a auto-organização, a importância da subjetividade etc. e, ao mesmo tempo, reivindicavam 
a "transformação" em todas as esferas da vida social, incluindo a afirmação feminista de que o "pessoal é político". Segundo Foucault - para ficar só nesse exemplo - foi esse momento que deu "significação política" ao seu estudo sobre a relação entre saber e poder (FOUCAULT, 1979 , p. 3), que seria central para entender a história da sexualidade (e da loucura e da prisão). Penso que esse contexto de efervescência política, que possibilitou a operação de desnaturalizar ou historicizar a sexualidade e o gênero, foi um momento teórico-epistemológico fundamental para repensar essas categorias, que passaram a ser cada vez mais concebidas como relações de poder.

Mas, as circunstâncias históricas que possibilitaram o surgimento de novas teorias como o feminismo e o pós-estruturalismo, também impõem mudanças nas relações e formas sociais, tornando necessária uma revisão constante do conteúdo das categorias que utilizamos para analisar a história atual. Nesse ponto, é válido voltar na discussão proposta por Butler e, mais particularmente, na reação que provocou com a resposta de Nancy Fraser, no texto Heterosexismo, falta de reconocimiento y capitalismo: una respuesta a Judith Butler. É importante informar aqui que em torno do debate entre Butler e Fraser foram produzidas muitas análises e discussões, em várias línguas, que não pretendo retomar. Apenas destaco uma consideração feita por Fraser e que nos interessa particularmente.

Fraser, que em seu marco teórico articula weberianismo e marxismo, defendeu nesse artigo que a opressão sexual não é de importância menor, nem menos material e real do que a opressão de classe. E longe de ser meramente simbólica, a opressão contra a população LGBT inclui graves desvantagens econômicas. No entanto, ela questionou a afirmação de Butler de que as lutas contra a regulação heterossexista ameaçariam a viabilidade do sistema capitalista. De acordo com o modelo teórico de Fraser, a sexualidade estaria ligada às questões de reconhecimento (cultural) e não de redistribuição (econômica). Por isso, não faria sentido a proposta de

\begin{tabular}{l|l}
\hline 70 & Um marxismo transviado
\end{tabular} 
Butler de considerar a sexualidade (articulada ao gênero) como parte da estrutura econômica, já que a regulação heterossexista não estrutura a divisão social do trabalho, nem o modo de exploração da força de trabalho (FRASER, 2000, p. 5, 7).

Interessante é que nesse debate, enquanto Fraser recorreu à definição de "econômico" de Marx presente no Prefácio de 1859 e em O capital, Butler construiu sua argumentação em torno da definição esboçada em $A$ ideologia alemã (e também em $A$ origem da família, da propriedade e do Estado, de Engels). Não penso que ambas as definições sejam antagônicas como se fosse necessário separar a verdadeira sentença da falsa. O complexo pensamento de Marx se constituiu como um processo dialético de rupturas e continuidades, não existindo (nesse caso) uma ruptura completa entre uma definição e outra. Ambas são válidas, dentro do mesmo marco teórico, de maneira que o que determina qual definição será mobilizada é o ponto de vista, o objeto e os objetivos da investigação. É preciso lembrar que Marx não vivenciou a intensa divisão do trabalho intelectual de hoje, lançando mão da segunda definição numa teorização de Filosofia da História e, da primeira, em uma análise de Economia.

A definição tratada por Fraser é mais específica e tem o grande mérito de possibilitar a investigação das nuances das relações de produção e das formas de exploração capitalistas, enfatizando como a consolidação do capitalismo demandou a criação de novas formas políticas, jurídicas e ideológicas que mediassem a acumulação expansionista do capital. Essa definição mais estrita do "econômico" salienta o papel da reprodução social a partir das particularidades da valorização do capital, como é o caso da diferenciação entre reprodução simples e reprodução ampliada. A categoria reprodução se refere aqui à reprodução da relação (de produção) capital e trabalho. Mesmo que essa seja a principal definição utilizada nas suas obras da "maturidade", penso que Marx não abandonou a definição dada nos manuscritos de 1845-1846. Essa definição permite enfatizar a dialética existente entre produção e reprodução (e não apenas as determinações mecânicas 
da primeira sobre a segunda), concebendo a reprodução social para além dos elementos e necessidades estritamente produtivos.

Assumir essa perspectiva de reprodução social, considerando a leitura que as feministas socialistas fazem do marxismo, coloca o questionamento de qual o peso que as relações de gênero e sexualidade possuem hoje para as relações de produção capitalistas. Voltando à resposta de Fraser, vale lembrar a sua discordância com a afirmação de Butler de que as lutas LGBT ameaçam o capitalismo em sua forma histórica atual, não sendo por acaso que os opositores principais dos direitos LGBT não sejam as corporações multinacionais, mas sim as forças conservadoras de caráter cultural e religioso (FRASER, 2000, p. 9).

De fato, é preciso diferenciar o peso das relações de sexualidade e gênero na formação do capitalismo e na reprodução deste nos dias atuais. Até mesmo porque no primeiro momento havia a necessidade de disciplinar os corpos de uma população majoritamente rural, de educá-la para uma vida urbana e industrial. A partir do século XIX, a humanidade pela primeira vez passou a crescer de forma acelerada em uma curva ascendente, não apenas devido ao avanço científico e tecnológico, mas também devido à maior difusão de técnicas-de-cuidado-de-si (relacionadas à sexualidade, higiene etc.) pelapopulaçãoeapolíticasdeaumentodanatalidadea partir deincentivo do casamento monogâmico heterossexual. Esse aumento exacerbado da população mundial tem gerado nas últimas décadas muitas críticas, diante da desenfreada degradação ambiental, a insustentabilidade das grandes cidades e os conflitos incessantes por disputa de território e recursos naturais.

Durante o século XX, houve mudanças significativas nas legislações e práticas que costumavam disciplinar e oprimir as mulheres, homossexuais e transexuais. O processo de transformação foi maior nos anos 1960 e 1970, sobretudo no que tange à conduta sexual, à parceria e à procriação. Na Europa ocidental e nos EUA, aos poucos, as legislações passavam a descriminalizar

\begin{tabular}{l|l}
\hline 72 & Um marxismo transviado
\end{tabular} 
a homossexualidade e a permitir a "sodomia"; além de alargar a liberação do divórcio, da venda de anticoncepcionais, da divulgação de informações sobre controle de natalidade e do aborto (HOBSBAWM, 1995, p. 316). Ao mesmo tempo, houve um rápido desenvolvimento dos métodos contraceptivos, que dava maior autonomia para a mulher, e também das tecnologias reprodutivas, que aumentam a chance de fertilidade das pessoas. Atualmente, há pesquisas em andamento para criar um embrião a partir de apenas gametas femininos ou só de masculinos e a partir de células-tronco, o que permitiria que casais do mesmo sexo tivessem filhos/as consanguíneos/as.

As profundas mudanças, iniciadas no ocidente nos anos 1960, dos costumes, concepções e práticas relacionadas à sexualidade levaram alguns/mas autores/as a denominar esse processo de "revolução sexual" . Por um lado, é bom salientar que essas transformações não foram consequências diretas do desenvolvimento científico ou da menor necessidade de incentivar o crescimento da reprodução humana. Antes, essas mudanças resultaram da ação de um sem número de agentes individuais e coletivos que historicamente enfrentaram as práticas heterossexistas e patriarcais, de forma organizada ou não.

Por outro lado, se houve transformações concretas significativas no modo de tratar a sexualidade, esse processo foi em verdade uma "revolução passiva sexual". Isso no sentido de que houve profundas alterações, mas manteve-se a lógica estruturante das relações de gênero e sexualidade: de fato uma maior liberalização e tolerância se efetivaram para mulheres e LGBT, bem como um maior distanciamento entre sexo e reprodução biológica, todavia, isso não significou que superamos as desigualdades de gênero e o heterossexismo, que fundamentam as opressões e as violências sexuais. Ao invés disso, o que se verifica, atualmente, é uma cultura que convive de maneira contraditória com as questões

${ }^{6}$ Ver por exemplo Therborn (2011). 
de gênero e sexualidade: de maior tolerância e visibilidade, mas também de aumento das formas de violência e invisibilidade. Essa contradição não é mais que uma expressão de uma cultura em mutação, no entanto, ainda hegemonicamente heterossexista e generificada.

Afirmar que o capital não tira proveito das relações de sexualidade e gênero porque as grandes corporações defendem os direitos LGBT não tem sentido. Não é porque as mesmas corporações fazem campanha a favor de mulheres, negros/as ou imigrantes, que isso significa que elas não lucram com as desigualdades em que estas/es estão inseridas/os. Como lembrou Cinzia Arruzza, se em uma definição lógica a expansão do capital prescinde das relações de gênero e de sexualidade, "uma formação social capitalista desprovida de opressão de gênero (em suas várias formas) jamais existiu". E questionou: "será que a opressão de gênero pode ser tão facilmente substituída por outros tipos de relações hierárquicas [baseadas em outros critérios e características humanas que não o "sexo"], capazes de parecer tão naturais e tão profundamente enraizadas na psique?" (ARRUZZA, 2015, p. 50-51).

A questão é que não precisamos desprezar o fato de que a lógica do capital pode continuar operando numa sociedade com relações de gênero e de sexualidade mais igualitárias. Por se fundamentar na relação entre trabalho assalariado e capital e na propriedade privada dos meios de produção, não é impensável um capitalismo futuro onde, por exemplo, as pessoas LGBT sejam maioria, ou mesmo que as mulheres trabalhem sob melhores condições ou ganhem maiores salários que os homens. No entanto, considerar as possibilidades e capacidades de valorização do capital, não quer dizer que elas estejam se efetivando, não pelo menos de forma hegemônica. Não só a produção de corpos continua dependendo (e reforçando) as relações de sexualidade e de gênero. Mas, o próprio capitalismo, como uma forma civilizatória, um modo de vida, apenas sobrevive manipulando e

\begin{tabular}{l|l}
\hline 74 & Um marxismo transviado
\end{tabular} 
permitindo a construção de valores, visões e maneiras de se identificar. As concepções, práticas e identidades de gênero e de sexualidade ajudam a dar sentido à vida dos indivíduos, contribuindo para definir a posição de cada um no processo de produção e de reprodução social, a inserção política nos espaços institucionais, os hábitos de consumo etc. Num capitalismo de desenvolvimento desigual e combinado, o movimento do capital se dá mobilizando relações sociais hierárquicas e que são interiorizadas como naturais.

As relações de gênero e sexualidade são formas de "sujeição" social que a um só tempo são reproduzidas e dinamizadas no movimento de acumulação do capital. Diante dos movimentos e reivindicações por igualdade e liberdade sexuais, essa dinâmica permitiu ao capitalismo assimilar rapidamente a diversidade sexual como um nicho de mercado, o que trouxe novas possibilidades de resistência e contradições. Palavras de ordem do início do movimento homossexual no Brasil como "sexo anal derruba o capital" passaram a perder o sentido diante da expansão e concentração da indústria pornográfica. Produtos e serviços voltados para o público gay e lésbico passaram a se multiplicar, as grandes marcas foram uma das primeiras a levantar a bandeira da visibilidade. Evidentemente, o acesso a esses produtos e serviços se dá para gays e lésbicas de algumas classes e, na maior parte do tempo, não contempla as travestis e transexuais.

De toda forma, por mais que tenha se formado um nicho de mercado para gays e lésbicas (de algumas classes), isso não significa que a diversidade sexual foi assimilada pelo circuito da reprodução econômica. O que está se construindo é uma sociedade que mantem o processo de socialização de suas crianças como indivíduos heterossexuais e generificados, mas com um estímulo crescente de respeito e tolerância às pessoas que por um acaso "desviarem" desse caminho ao longo da vida. Mas, a diversidade sexual e de gênero continua sendo o outro, o diferente, que pode ser aceito ou eliminado a depender do contexto e das correlações de força. O heterossexismo segue ainda fundamental para a reposição da divisão sexual 
do trabalho e da construção da mulher como a principal responsável pelo trabalho reprodutivo. Como forma de inteligibilidade da realidade social, ele continua sendo prática hegemônica, que contribui para formar um sentido à vida das pessoas e que pode voltar a ser prática oficialmente obrigatória no caso das taxas de natalidade apresentar de novo quedas bruscas.

$\mathrm{O}$ "regime sexual" atual que carrega o velho e o novo, elementos conservadores e progressistas, não pode ser compreendido sem identificar a lógica que lhe estrutura. Um dos avanços realizados na leitura feminista da teoria marxista da reprodução social foi permitir compreender como todos os indivíduos estão inseridos nesse "regime político", que conduz a construção de corpos e de seus desejos, afetos e práticas-de-si. Mesmo diante das múltiplas formas de resistência e de enfrentamento, estamos todos/as inseridos/as em sua lógica. Somos todos/as sujeitados/as a ela. Influenciado por Foucault, Nicos Poulantzas afirmou que "o corpo não é uma simples unidade biológica, mas uma instituição política” (POULANTZAS, 1980, p. 34). Essa constatação deixa sem sentido a visão de que a reivindicação de o "corpo é meu" seja individualista e liberal. Não só porque o liberalismo se tornou hegemônico com a sujeição de corpos, mas, sobretudo, porque a autonomia individual sobre o corpo se tornou pressuposto para a autonomia coletiva.

Nesse sentido, as lutas pela diversidade sexual e de gênero não são meramente particulares. Porém, a "política de identidade" empreendida pelo movimento LGBT, e constituída em torno do combate ao preconceito e discriminação e da afirmação das identidades subalternas, é uma forma de particularizar a luta. Essa forma, apesar de ter propiciado muitos ganhos, impediu o próprio movimento de insistir numa perspectiva que "generalizasse", "universalizasse" a questão da sexualidade e do gênero, e que facilitasse o entendimento de que, assim como as relações de classe, essa questão toca "tudo" e a todos/as. Isso prejudicou a compreensão do movimento LGBT como um momento de enfrentamento das formas hegemônicas que

\begin{tabular}{l|l}
\hline 76 & Um marxismo transviado
\end{tabular} 
constituem a reprodução social e de como a luta pela diversidade sexual e de gênero pode (em certos contextos e condições) ameaçar o capitalismo.

\section{O marxismo e as lutas de sexualidade e gênero}

A discussão elaborada até aqui tentou apontar alguns caminhos para o desenvolvimento de uma análise das relações de sexualidade e gênero, fundamentada na articulação do marxismo com as contribuições do feminismo e do pós-estruturalismo. A proposta dessa seção é refletir um pouco mais sobre como a teoria marxista pode auxiliar o entendimento das lutas pela diversidade sexual e de gênero, enfatizando, mais especificamente, como o marxismo pode oferecer um método capaz de compreender a dinâmica relacional entre as múltiplas desigualdades e opressões sociais, sem hierarquiza-las de antemão, e ao mesmo tempo, um método de construção da análise de conjuntura e de estratégia política.

Se o fato de as relações de produção capitalistas terem se expandido nas últimas décadas dá vida e sentido ao marxismo, isso não implica que devemos voltar ao erro (ou permanecer nele) de desenvolver uma forma de teorização que hierarquize as opressões e estabeleça previamente quais lutas são prioritárias na agenda política. É, nesse sentido, que uma leitura dialética da produção e reprodução social pode ajudar. Sobretudo, na interpretação feminista do marxismo, que entende o termo reprodução social de maneira mais precisa: "a manutenção e reprodução da vida, em nível diário e geracional", designando "a forma na qual o trabalho físico, emocional e mental necessário para a produção da população é socialmente organizado" (ARRUZZA, 2015, p. 55). É claro que esse não é um processo meramente material, mas também simbólico - e, por isso, o pós-estruturalismo oferece ferramentas para ajudar a compreender 
a relação dialética que existe entre ambos. A categoria de reprodução social permite, ainda, articular as relações de classe, gênero e sexualidade de maneira orgânica e não ocasional. Como afirmou Arruzza, "a reprodução social é também determinante na formação da subjetividade e, portanto, das relações de poder". Todavia,

estas relações não podem ser concebidas como puramente intersecções acidentais e contingentes: vê-las pelas lentes da reprodução social nos permite identificar a lógica organizacional destas intersecções sem por isso excluir o papel desempenhado pela luta, ou desconsiderar a existência de fenômenos contingentes e práticas em geral (ARRUZZA, 2015, p. 56).

A proposta da autora reconhece a existência de relações de poder que colocam "limites" e fazem "pressão" sobre os indivíduos, mas é aberta para a percepção da contingência, que em parte existe graças à dinâmica das lutas. A contingência implica em admitir, e isso a própria história nos mostra, que em contextos diferentes as lutas sociais têm pesos e formas diferentes na disputa e na mobilização políticas e nas mudanças sociais (ideológicas, culturais, institucionais, econômicas etc.).

Sobre isso, Armando Boito observou que, em cada momento histórico, as lutas têm centralidades diferentes na "cena" política. As lutas dos/as negros/as nos EUA, nos anos 1960, ou as manifestações na França a favor e contra o casamento entre pessoas do sexo, em 2013, estavam relacionadas à questão racial e à questão sexual (isto é, de sexualidade e gênero), respectivamente, e não à classe social. Contudo, para ele, num momento de crise revolucionária, as classes são centrais (informação verbal) ${ }^{7}$. Penso que vale apontar que, mesmo diante da centralidade das classes, um processo de "crise" de revolução socialista

\footnotetext{
7 Trecho da intervenção de Armando Boito durante debate ocorrido na sessão plenária "O Marxismo e os movimentos sociais contemporâneos", do VIII Colóquio Internacional Marx Engels, em Campinas (SP), julho de 2015.
}

\begin{tabular}{l|l}
\hline 78 & Um marxismo transviado
\end{tabular} 
provoca profundos efeitos nas outras relações de poder e, além disso, essa "crise" não nasce necessariamente a partir das reivindicações de classe ou somente atrelada a elas.

Por fim, a análise pós-estruturalista desenvolveu todo um instrumento teórico para o estudo, dentre outras questões, da construção cotidiana do gênero e da sexualidade, das formas de resistência moleculares e da lógica heterossexista e masculina hegemônica, dos elementos simbólicos e das dinâmicas institucionais que participam desse processo. No entanto, o pós-estruturalismo - como toda teoria - apresenta limites de análise, de maneira que penso ser possível selecionar aquilo o que ele tem de mais radical e interessante, debatendo criticamente com os elementos teóricometodológicos que podem dificultar a disputa política. Um exemplo é a tendência do pós-estruturalismo de ser avesso à organização política e mobilização coletiva e, sobretudo, à construção de uma forma de luta e de resistência organizada a partir de um projeto de uma nova sociedade e de uma nova "normatividade". Ao se especializarem no exame crítico das práticas normatizadoras, pós-estruturalistas como Foucault e Butler, na maior parte do tempo, silenciaram sobre as bases normativas que alicerçaram suas próprias críticas ${ }^{8}$. Essa rejeição de evidenciar e justificar as próprias bases normativas vem da mesma recusa de conceber uma estratégia articulada a um programa político e um projeto societal.

Não se pode desprezar a importância, defendida pelo pósestruturalismo, das formas de luta moleculares, que são o substrato de uma cultura política de resistência e da organização de movimentos coletivos. Contudo, é urgente voltarmos a Gramsci para compreender que a complexidade da estratégia vem da complexidade da dinâmica das lutas. Gramsci, estudando a luta de classes, valorizou a disputa molecular e difusa, mas como para ele a hegemonia se constituía

${ }^{8}$ Sobre isso, ver o comentário de Fraser sobre normatividade nos trabalhos de Butler e Foucault, em Cyfer e Neves (2011, p. 205). 
privilegiadamente na ação dos "aparelhos", a luta deve passar necessariamente no e pelo Estado ou por meio do associativismo presente na sociedade civil. Sobretudo, nessa última, as classes subalternas teriam mais chance de se fortalecer antes de alcançar o Estado; seja "ocupando" espaços institucionais mas, principalmente, criando organizações coletivas próprias, capazes de empreender uma forma de luta sistemática, construir alianças e disputar a visão de mundo das pessoas a partir de uma certa estratégia política.

Essa questão se tornou mais evidente para o movimento LGBT no Brasil recente. A formação e fortalecimento de um movimento coletivo próprio, nos anos 1970 e 1980, e o estreitamento da relação entre movimento e Estado, nos anos 1990 e 2000, foram fundamentais para a construção da visibilidade que a questão LGBT goza atualmente. A ação coletiva LGBT não se desenvolveu sem se articular com as lutas de classe. Quando as políticas de combate à homofobia passaram a ser implementadas pelo governo federal e os direitos LGBT, a serem discutidos no parlamento e no judiciário, o movimento passou a fazer parte de uma correlação de forças de classes e grupos sociais que dá sustentação ao Estado e que já existia. O próprio Golpe de 2016 mostrou como neoliberalismo e neoconservadorismo evangélico (principal adversário político do movimento hoje) se articularam, barrando, entre outras coisas, o avanço das políticas e direitos LGBT. Além disso, este processo evidenciou a condição de classe do movimento, uma vez que o conjunto de medidas de austeridade e de ajuste pode ser prejudicial ao conjunto do movimento que é composto por militantes pertencentes às classes trabalhadoras (TOITIO, 2016).

É urgente questionar não apenas sobre a dinâmica articuladora das relações de poder, mas das próprias lutas subalternas. Nesse sentido, um marxismo transviado pode contribuir para a compreensão da multiplicidade das formas de luta e de relações de poder, considerando: as formas dispersas de controle sobre o corpo, como elemento material que é alvo de disciplinamento e é, ao mesmo tempo, portador da força, da capacidade de trabalhar; a formação

\begin{tabular}{l|l}
\hline 80 & Um marxismo transviado
\end{tabular} 
e a disputa ideológica presente nas instituições e organizações civis; e o Estado como um aparelho "especial" ${ }^{\text {" }}$ que pode agir para alterar significativamente a construção de concepções e práticas, coibir e incentivar a propagação de determinados discursos. Ao mesmo tempo, sem desconsiderar as formas de resistências "interpessoais" e espontâneas, mas apontando também para a fundamental importância das ações construídas coletivamente, de forma sistemática, defendendo um projeto de sociedade próprio. Aqui, as estratégias devem ser traçadas não apenas dentro dos "limites" do poder, mas em torno da historicidade das relações de poder e daquilo que essas têm de mais radical, o que passa pela contestação da forma política liberaldemocrática, em cujas instituições as classes e grupos subalternos estão sub-representados. Mas, se o projeto socialista continua vivo, ele não pode ser mais concebido de modo destacado das outras relações de poder, pois falar em revolução hoje significa mudar radicalmente o conjunto dessas relações.

\section{Referências bibliográficas}

ARRUZZA, C. Considerações sobre gênero: reabrindo o debate sobre patriarcado e/ou capitalismo. Outubro, ed. 23, 2015.

BENTO, B. O que pode uma teoria? estudos transviados e a despatologização das identidades trans. Florestan, n. 2, 2014.

BUTLER, J. El marxismo y lo meramente cultural. New Left Review, n. 2, mai-jun. 2000.

CYFER, I. e NEVES, R. Entrevista com Nancy Fraser. ABREU, M. A. (org.) Redistribuição, reconhecimento e representação: diálogos sobre igualdade de gênero. Brasília: Ipea, 2011.

\footnotetext{
${ }^{9}$ A ideia de Estado como aparelho "especial" é de Poulantzas (1980).
} 
FOUCAULT, M. Microfísica do poder. 17. ed. Rio de Janeiro: Graal, 1979.

. História de sexualidade I: a vontade de saber. Rio de Janeiro: Graal, 1988.

FRASER, N. "Heterosexismo, falta de reconocimiento y capitalismo: una respuesta a Judith Butler". New Left Review 2, mai./jun, 2000.

GRAMSCI, A. Cadernos do cárcere. 4. ed. Rio de Janeiro: Civilização Brasileira, v. 1, 2006.

HOBSBAWM, E. A era dos extremos: o breve século XX: 1914-1991. São Paulo: Companhia das Letras, 1995.

JESSOP, B. State Power: a strategic-relational approach. Cambridge/ Malden: Polity Press, 2007.

LUKÁCS, G. Para uma ontologia do ser social I. São Paulo: Boitempo, 2012.

MARX, K. Ad Feuerbach (1845). In: MARX, K. e ENGELS, F. A ideologia alemã. São Paulo: Boitempo, 2007.

POULANTZAS, N. O Estado, o Poder, o Socialismo. Rio de Janeiro: Graal, 1980.

THERBORN, G. Sexo e poder: a família no mundo 1900-2000. 2. ed. São Paulo: Contexto, 2011.

TOITIO, R. D. Cores e contradições: a luta pela diversidade sexual e de gênero sob o neoliberalismo brasileiro. Campinas, 2016. Tese (Doutorado em Ciências Sociais), IFCH/Unicamp.

WILLIAMS, R. Cultura e materialismo. São Paulo: Ed. Unesp, 2011.

\begin{tabular}{l|l}
\hline 82 & Um marxismo transviado
\end{tabular} 